\title{
SCIDiCe
}

\author{
International Journal of Dentistry and Oral Science (IJDOS) \\ ISSN: 2377-8075
}

\section{Knowledge and Awareness of Prosthetic Restoration of Endodontically Treated Teeth among the Dental Students and Dentist of Saudi Arabia}

Research Article

Maryam Alghamdi ${ }^{*}$, Albatool Alhadidi ${ }^{2}$, Malak Almusfir ${ }^{2}$, Njood Bin Jahlan $^{2}$, Sarah Almowallad ${ }^{2}$, Shaza Shareef ${ }^{2}$, Raghad Alrefaei ${ }^{2}$, Khalid Aboalsha$\mathrm{mat}^{3}$, Adham Niyazi ${ }^{4}$

\footnotetext{
${ }^{1}$ Faculty of Dentistry, Department of Dentistry, General Dentist, Umm Al-Qura University, Makkah, Saudi Arabia.

${ }^{2}$ Faculty of Dentistry, Department of Dentistry, Dental Student, Batterjee Medical College, Jeddah, Saudi Arabia.

${ }^{3}$ Faculty of Dentistry, Preventative Dentistry Department, Dental Public Health Division, Umm Al-Qura University, Makkah, Saudi Arabia.

${ }^{4}$ Faculty of Dentistry, Preventative Dentistry Department, General Dentist, Batterjee Medical College, Jeddah, Saudi Arabia.
}

\section{Abstract}

Introduction: After endodontic treatment, teeth may have extensive damage from trauma, caries, and the treatment itself. Intracanal posts will be needed to retain and increase the longevity of teeth. The most common method used for this is post and core for endodontically treated teeth.

Aim: The aim of this study was to measure and assess knowledge and awareness about prosthetic restoration of endodontically treated teeth among dental students and dentists in Saudi Arabia.

Methods: This cross-sectional study involved 202 dental students and dentists who were recruited via online questionnaire. The questionnaire was validated through piloting. T-tests, linear regressions, chi-square, and ANOVA were used for statistical analyses, and a probability value of $<0.05$ was set for statistical significance.

Results: Participants had a mean score of 10.65 with a standard deviation (SD) of 3.011 for 16 questions regarding endodontic treatment and dental post types. T-tests showed that females and Saudis had significantly higher knowledge scores than males and non-Saudis. Linear regression showed a significant direct relationship between total knowledge scores and years of experience $(p=$ 0.004 , r-squared $=0.041)$. Results of linear regression, t-test, and ANOVA showed no significant relationships of total knowledge score with age, qualifications, marital status, region, or practice type.

Conclusion: Overall knowledge among dental interns and dentists about endodontically treated teeth was moderate and needs improvement through more study regarding the topic, which should be made available in Saudi Arabia to more participants.

Keywords: Knowledge; Awareness; Prosthetic Restoration; Endodontically Treated Teeth; Dental Students; Dentist, Saudi Arabia.

\section{Background}

Endodontics transact with the treatment of diseased, inflamed, or infected dental pulp tissue through root canal treatment (RCT), pulp capping, pulpal regeneration, pulpotomy, apexification, hemisection, periradicular surgery, and apicoectomy [1, 2]. The dental pulp includes nerves, fibrous tissue, arterioles, venules, and lymphatic tissue [1]. The chances of saving badly damaged teeth increase with endodontic treatment [3], and therefore, the purpose of endodontic and restorative treatment is to restore the normal occlusion and function of the tooth and maintain the stability of the dental arch [4]. Subsequently, the longevity of teeth that are endodontically treated depends primarily on the amount of missing structure and the ability of the restorative materials to replace the missing tooth structure [5].

The successful treatment of infected teeth depends not only on excellent endodontic treatment but also on excellent reconstruction of the tooth [1]. Studies have reported that the primary cause of negative results is the failure of the restoration rather than the failure of the endodontic treatment itself [3]. In light of this, dentists and their patients undergoing endodontic treatments should follow a proper treatment plan with respect to endodontic and restorative therapy $[3,6]$. The most important factor for the clinical success of endodontic therapy is the final restoration be-

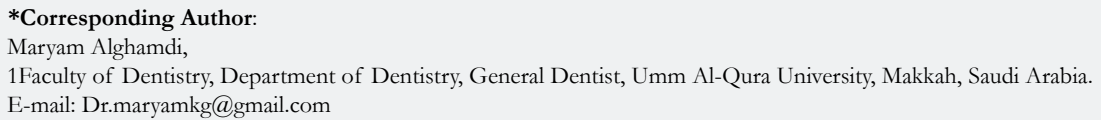

Citation: Maryam Alghamdi, Albatool Alhadidi, Malak Almusfir, Njood Bin Jahlan, Sarah Almowallad, Shaza Shareef, et al., Knowledge and Awareness of Prosthetic Restoration of Endodontically Treated Teeth among the Dental Students and Dentist of Saudi Arabia. Int I Dentistry Oral Sci. 2021;8(7):3284-3288. doi: http://dx.doi.org/10.19070/2377-8075-21000668

Copyright: Maryam Alghamdi ${ }^{\circ} 2021$. This is an open-access article distributed under the terms of the Creative Commons Attribution License, which permits unrestricted use, distribution and reproduction in any medium, provided the original author and source are credited. 
cause improper restoration after RCT may be one of the causes of tooth extractions [6]. Different strategies have been proposed for the restoration of endodontically treated teeth [7-9], including the use of posts and cores [7], direct resin composites, and amalgam fillings [10].

Traditionally, the most common method used to retain badly compromised teeth after endodontic treatment is the application of post and core followed up with full-coverage crowns to protect the tooth from fractures in the future [11]. A recently published randomized controlled trial revealed the reliability of posts used clinically in endodontically treated teeth, regardless of the post's rigidity [12]. The dentine-like glass-fiber posts, which are the newest type, work best when combined with a composite core [13]. The ideal post for endodontically treated teeth should meet many other requirements as well, and this requires knowledge about the preservation of tooth structure, ferrule effect, retrievability, maintenance of resistance, and retention and failure mode [7, 14].

The awareness of dental practitioners about the prosthetic restoration of endodontically treated teeth depends on their years of practice or education, their experience, and other factors, but there is a lack of information about this topic among dentists in Saudi Arabia and also worldwide. Thus, this study aimed to measure and assess knowledge and awareness about the prosthetic restoration of endodontically treated teeth among dental students and dentists in Saudi Arabia.

\section{Objectives}

The main aim of this study was to measure and assess knowledge and awareness about the prosthetic restoration of endodontically treated teeth among dental students and dentists studying and working in Saudi Arabia.

\section{Methods}

This was a cross-sectional study using a questionnaire that assessed levels of awareness about the prosthetic restoration of endodontically treated teeth. A convenient sampling technique was used to recruit participants from all over Saudi Arabia. Because of the required social distancing due to COVID-19 in Saudi Arabia, which coincided with the period of data collection from February 2021 to February 2022, recruiting was conducted via social media platforms (Instagram, Twitter, Snapchat, WhatsApp, ResearchGate, and Facebook). The inclusion criteria were current dental students, interns, or dentists, whether working at the time or not, who studied or practiced in Saudi Arabia. All participants who refused to sign the informed consent form were excluded. The research team distributed 580 online self-administered questionnaires in English, which participants answered anonymously and voluntarily in their free time. There was an informed consent notice at the beginning of the questionnaire, and participants were advised that, by answering the questionnaire, they were agreeing to the informed consent. The questionnaire took approximately 3-5 minutes to complete.

The questionnaire used in this study was derived from a validated questionnaire used in a previous study [1]. It consisted of 25 questions organized in two sections. The first section collected demographic data about the participants regarding gender, age, city of residence, nationality, type of practice, marital status, years of education/study and experience in dentistry. The second section contained 16 yes/no questions that assessed the participant's awareness about prosthetic restoration of endodontically treated teeth in dental services. The total knowledge score was calculated by totaling the scores of all the knowledge questions. The collected data were analyzed using version 21 of SPSS software (IBM Corp., Armonk, NY, USA). T-tests, linear regressions, chi-square, and ANOVA were used for statistical analyses, and a probability value of $<0.05$ was set for statistical significance. Before conducting the study, ethical approval was obtained from the Institutional Review Board (IRB) of Batterjee Medical College, Faculty of Dentistry, research proposal number [RES-2021-0040].

\section{Results}

This study's research questionnaire was answered by 202 participants, who had a mean age of 28.37 with a standard deviation (SD) of 17.01. The collected demographic data (gender, region, nationality, marital status, practice type, and qualification) of the participants are shown in Table 1.

Table 1. Participants' demographic data.

\begin{tabular}{|c|c|c|c|}
\hline \multicolumn{2}{|c|}{ Variable } & Number (N) & Percentage (\%) \\
\hline \multirow{4}{*}{ Gender } & Male & 44 & $21.80 \%$ \\
\cline { 2 - 4 } & Female & 158 & $78.20 \%$ \\
\hline \multirow{4}{*}{ Region } & West & 117 & $57.90 \%$ \\
\cline { 2 - 4 } & East & 20 & $9.90 \%$ \\
\cline { 2 - 4 } & Central & 40 & $19.80 \%$ \\
\cline { 2 - 4 } & South & 11 & $5.40 \%$ \\
\cline { 2 - 4 } & North & 14 & $6.90 \%$ \\
\hline \multirow{3}{*}{ Marital status } & Saudi & 160 & $79.20 \%$ \\
\cline { 2 - 4 } & Non-Saudi & 42 & $20.80 \%$ \\
\cline { 2 - 4 } & Married & 47 & $23.30 \%$ \\
\hline \multirow{3}{*}{ Type of practice } & Non-married & 155 & $76.70 \%$ \\
\cline { 2 - 4 } & Governmental & 55 & $26.70 \%$ \\
\cline { 2 - 4 } & Private & 59 & $26.70 \%$ \\
\hline \multirow{3}{*}{ Qualifications } & Not currently & & \\
& working & 88 & $43.60 \%$ \\
\cline { 2 - 4 } & Student & 140 & $69.70 \%$ \\
\cline { 2 - 4 } & General dentist & 39 & $18.90 \%$ \\
\cline { 2 - 4 } & Specialist & 10 & $5 \%$ \\
\hline & Consultant & 13 & $6.50 \%$ \\
\hline
\end{tabular}


The participants were asked 16 questions to assess their knowledge about the prosthetic restoration of endodontically treated teeth and the various post types used. The questions and the results of the participants' answers are provided in Table 2. The correct answers were added to the total knowledge score, which had a possible range of $0-16$, representing the lowest level of knowledge to the highest level of knowledge. The participants had a mean total knowledge score of 10.65, with an SD of 3.011. More details are given in Table 2 .

The total knowledge scores were compared for the different demographic variables, as shown in Table 3 . The results of the t-test showed that females and Saudis had significantly better knowledge scores than males and non-Saudis. Using linear regression, a significant direct relationship was revealed between the total knowledge score and years of experience $(\mathrm{p}=0.004$, $\mathrm{r}$-squared $=$ 0.041). Using linear regression, t-test, and ANOVA, it was shown that there were no significant relationships between total knowledge scores and age, qualifications, marital status, region, or type of practice. These results are provided in Table 3.

\section{Discussion}

This study was conducted to measure the levels of knowledge and awareness about the prosthetic restoration of endodontically

Table 2. Participant answers to questions regarding the prosthetic restoration of endodontically treated teeth.

\begin{tabular}{|c|c|c|}
\hline \multicolumn{2}{|c|}{$\begin{array}{c}\text { Questions assessing knowledge about prosthetic restoration of end- } \\
\text { odontically treated teeth }\end{array}$} & \multirow{2}{*}{$\frac{\text { Number (\%) }}{190(94.1 \%)}$} \\
\hline \multirow{3}{*}{$\begin{array}{l}\text { 1. Prosthetic rehabilitation can restore the lost } \\
\text { structure of teeth after endodontic therapy. }\end{array}$} & Yes* & \\
\hline & No & $5(2.5 \%)$ \\
\hline & I do not know & $7(3.5 \%)$ \\
\hline \multirow{3}{*}{$\begin{array}{l}\text { 2. Endodontically treated teeth dentin does } \\
\text { not dry out over time and does not undergo } \\
\text { changes in collagen cross-linking. }\end{array}$} & Yes & $23(11.4 \%)$ \\
\hline & No* & $129(63.9 \%)$ \\
\hline & I do not know & $50(24.8 \%)$ \\
\hline \multirow{3}{*}{$\begin{array}{l}\text { 3. Endodontically treated teeth are more brittle } \\
\text { than non-endodontically treated teeth. }\end{array}$} & Yes* & $187(92.6 \%)$ \\
\hline & No & $15(7.4 \%)$ \\
\hline & I do not know & $0(0 \%)$ \\
\hline \multirow{3}{*}{$\begin{array}{l}\text { 4. Endodontically treated teeth are less suscep- } \\
\text { tible to fracture than non-treated teeth. }\end{array}$} & Yes & $41(20.3 \%)$ \\
\hline & No* & $158(78.2 \%)$ \\
\hline & I do not know & $3(1.5 \%)$ \\
\hline \multirow{3}{*}{$\begin{array}{l}\text { 5. Loss of tooth structure due to caries and } \\
\text { trauma contributes to fracture of endodonti- } \\
\text { cally treated teeth. }\end{array}$} & Yes* & $164(81.2 \%)$ \\
\hline & No & $24(11.9 \%)$ \\
\hline & I do not know & $14(6.9 \%)$ \\
\hline \multirow{3}{*}{$\begin{array}{l}\text { 6. Crown restorations cannot fail due to the } \\
\text { loss of tooth structure. }\end{array}$} & Yes & $23(11.4 \%)$ \\
\hline & No* & $162(80.2 \%)$ \\
\hline & I do not know & $17(8.4 \%)$ \\
\hline \multirow{3}{*}{$\begin{array}{l}\text { 7. Use of post and core can strengthen end- } \\
\text { odontically treated teeth. }\end{array}$} & Yes* & $143(70.8 \%)$ \\
\hline & No & $58(28.7 \%)$ \\
\hline & I do not know & $1(0.5 \%)$ \\
\hline \multirow{3}{*}{$\begin{array}{l}\text { 8. It is not a primary function of posts to pro- } \\
\text { vide retention to the core to support coronal } \\
\text { restoration. }\end{array}$} & Yes & $28(13.9 \%)$ \\
\hline & No* & $167(82.7 \%)$ \\
\hline & I do not know & $7(3.5 \%)$ \\
\hline \multirow{3}{*}{$\begin{array}{l}\text { 9. The shearing forces acting on anterior teeth } \\
\text { are more frequently restored with posts than } \\
\text { with posterior teeth. }\end{array}$} & Yes* & $80(39.6 \%)$ \\
\hline & No & $67(33.2 \%)$ \\
\hline & I do not know & $55(27.2 \%)$ \\
\hline \multirow{3}{*}{$\begin{array}{l}\text { 10. Selection of a post design and system is } \\
\text { not important for the longevity and long-term } \\
\text { success of endodontic treatment. }\end{array}$} & Yes & $31(15.3 \%)$ \\
\hline & No* & $162(80.2 \%)$ \\
\hline & I do not know & $9(4.5 \%)$ \\
\hline \multirow{3}{*}{ 11. Active and passive posts. } & Yes* & $91(45 \%)$ \\
\hline & No & $37(18.3 \%)$ \\
\hline & I do not know & $74(36.6 \%)$ \\
\hline \multirow{3}{*}{ 12. Parallel and tapered posts. } & Yes* & $135(66.8 \%)$ \\
\hline & No & $28(13.9 \%)$ \\
\hline & I do not know & $39(19.3 \%)$ \\
\hline \multirow{3}{*}{ 13. Custom-cast posts and cores. } & Yes* & $166(82.2 \%)$ \\
\hline & No & $14(6.9 \%)$ \\
\hline & I do not know & $22(10.9 \%)$ \\
\hline \multirow{3}{*}{ 14. Prefabricated posts and cores. } & Yes* & $166(82.2 \%)$ \\
\hline & No & $11(5.4 \%)$ \\
\hline & I do not know & $25(12.4 \%)$ \\
\hline \multirow{3}{*}{ 15. Ceramic and zirconium posts. } & Yes* & $102(50.5 \%)$ \\
\hline & No & $42(20.8 \%)$ \\
\hline & I do not know & $58(28.7 \%)$ \\
\hline \multirow{3}{*}{ 16. Fiber posts. } & Yes* & $190(94.1 \%)$ \\
\hline & No & $7(3.5 \%)$ \\
\hline & I do not know & $5(2.5 \%)$ \\
\hline
\end{tabular}

*The correct answer. 
Table 3. Total knowledge about prosthetic restoration of endodontically treated teeth in relation to gender, region, nationality, marital status, type of practice, and qualifications.

\begin{tabular}{|c|c|c|c|}
\hline \multirow{2}{*}{\multicolumn{2}{|c|}{ Variable }} & \multicolumn{2}{|c|}{$\begin{array}{l}\text { Total knowledge about prosthetic res- } \\
\text { toration of endodontically treated teeth }\end{array}$} \\
\hline & & Mean (SD) & P-value \\
\hline \multirow{2}{*}{ Gender } & Male & $9.89(2.6)$ & \multirow{2}{*}{0.036} \\
\hline & Female & $10.87(3.09)$ & \\
\hline \multirow{5}{*}{ Region } & West & $10.7(3.11)$ & \multirow{5}{*}{0.56} \\
\hline & East & $11.1(3.01)$ & \\
\hline & Central & $10.88(2.8)$ & \\
\hline & South & $10(2.37)$ & \\
\hline & North & $9.57(3.27)$ & \\
\hline \multirow{2}{*}{ Nationality } & Saudi & $11(2.97)$ & \multirow{2}{*}{0.002} \\
\hline & Non-Saudi & $9.36(2.84)$ & \\
\hline \multirow{2}{*}{ Marital status } & Married & $10.72(2.93)$ & \multirow{2}{*}{0.864} \\
\hline & Non-married & $10.64(3.04)$ & \\
\hline \multirow{3}{*}{ Type of practice } & Governmental & $11.18(2.82)$ & \multirow{3}{*}{0.249} \\
\hline & Private & $10.68(3.18)$ & \\
\hline & $\begin{array}{l}\text { Not currently } \\
\text { working }\end{array}$ & $10.32(3)$ & \\
\hline \multirow{2}{*}{ Qualifications } & Student & $10.66(2.98)$ & \multirow{2}{*}{0.967} \\
\hline & Dentist & $10.64(3.08)$ & \\
\hline
\end{tabular}

treated teeth among dental students and dentists in Saudi Arabia. The results showed better understanding and awareness of this treatment method among Saudis and female participants than among non-Saudis and males. The participants had a mean total knowledge score $(10.65, \mathrm{SD}=3.011)$ that was higher than the midpoint.

The response rate for this study was higher than the study conducted in Jazan, which might be due to our study being distributed throughout Saudi Arabia, as opposed to the local nature of the Jazan study [1]. However, the rate was less than that for other studies measuring knowledge and attitudes about the techniques and strategies for restoring endodontically treated teeth that were conducted in Saudi Arabia, Palestine, and India [15-19].

The section of this study's questionnaire assessing knowledge and attitudes had a total of 16 questions. The first 10 questions measured the respondent's knowledge about endodontically treated teeth. The first questions regarding prosthetic rehabilitation were correctly answered by $94.1 \%$ of the participants, which is a very good response rate and is higher than the percentage of correct respondents $(84,90.3 \%)$ in the Jazan study [1]. In addition, the third question had more correct responses in our study (187, $92.6 \%)$ than in the Jazan study $(80,86.0 \%)$ [1]. The respondents in our study showed generally good awareness of the topics of the remaining questions, with more than $70 \%$ of the participants answering correctly.

In the second section of the questionnaire discussing posts and their types, the question asking about active versus passive posts had the lowest percentage of correct answers, with only $91(45 \%)$ respondents answering correctly, as compared to the study in Jazan, where $94.6 \%$ of respondents had awareness [1]. According to a study conducted in Germany regarding why, when, and how general practitioners restore endodontically treated teeth, the results showed that general practitioners preferred to work with active prefabricated metallic posts more than passive prefabricated metallic posts [20]. In the present study, with regard to parallel versus tapered posts, 135 of the participants showed awareness of this choice, with $66.8 \%$ answering correctly, which is less than the number of participants correctly answering this question in the Jazan study $(90,96.7 \%)$ [1]. An in vitro study that evaluated the retention and fracture resistance of different fiber-reinforced posts showed that the retention values for parallel posts were significantly better than those for tapered posts, and tapered posts had a higher mean load to fracture than parallel posts [21]. In the present study, with regard to awareness of custom-cast posts and cores versus prefabricated posts and cores, $166(82.2 \%)$ of the 202 participants answered correctly, showing awareness of these types. In addition, only $102(50.5 \%)$ participants were aware of ceramic and zirconium posts. In a Palestinian study conducted in $2015,47.7 \%$ of participants preferred prefabricated metallic posts with a core build-up over custom-cast posts $(15.9 \%)$ or non-metallic posts $(22.7 \%)$ [18]. The most common recognizable type of posts was the fiber posts, with a large number of correct answers by participants $(190,94.1 \%)$, which was more than the percentage in the Jazan study $(84,90.3 \%)$. The differences in participant answers between our study and the Jazan study [1] can be attributed to the methods of education differing from one region to another, which affects the knowledge levels of participants.

According to the mean of correct answers, the awareness level in this study was moderate, but when compared to the Jazan study, our study respondents' awareness is considered poor. This might be due to most of the participants in this study being undergraduate students, whereas in the study conducted in Jazan [1], all of 
the participants were dentists, who had more experience and knowledge than this study's participants.

This study is very important given the results of another study conducted in Saudi Arabia about the knowledge, attitudes, and practice regarding restoring endodontically treated teeth showing that crown fractures were the most common cause of failure of endodontically treated teeth, followed by endodontic failure and root fracture. These factors can be prevented or decreased by more widespread knowledge and awareness among dental practitioners about the best practices for prosthetic restoration of endodontically treated teeth and the use of dental posts.

Despite the importance of this study, some limitations apply, including the participants not being a sample representative of the entire country and the use of more specific questions regarding the posts used in patient cases. Further studies are needed regarding this topic to gauge the proper level of knowledge and awareness among all dental practitioners in Saudi Arabia. In addition, educational curricula, workshops, and clinical training about dental posts and the different types should be provided for dentists and dental students in all areas of Saudi Arabia in order to have more widespread high levels of knowledge of the subject.

\section{Conclusion}

The goal of this study was to assess and measure dental students' and dentists' awareness and understanding of the prosthetic restoration of endodontically treated teeth. This is essential knowledge that needs to be evaluated for the better development of new curricula and continuing professional development. The majority of Saudi dental students and doctors involved in this study had decent levels of education and expertise with regard to the prosthetic restoration of endodontically treated teeth, and the t-test results clearly showed that Saudi nationals had considerably better knowledge than non-Saudis. It was also discovered that women have substantially more knowledge than men. In addition, there was a significant direct relationship between the total knowledge score and years of experience. There was no correlation between total knowledge score and age, qualification, marital status, type of practice, or region. The dentists are extremely well educated, and the majority of them already have extensive practice experience in the field, but the dental students also had a wealth of knowledge. Doctors and students are well versed in the prosthetic restorations that can be performed following endodontic therapy. However, further investigation involving all dental care providers across various demographic variables in Saudi Arabia is required to provide more precise results.

\section{Acknowledgments}

We acknowledge and are very grateful to all the dentists and dental students who completed the questionnaire.

\section{References}

[1]. Alaki BH. Knowledge and Awareness of Prosthetic Restoration of Endodon- tically Treated Teeth among the Dental Doctors of Jazan, Saudi Arabia. Saudi J Oral Dent Res. 2021;6(1):39-43.

[2]. Maroulakos G, Nagy WW, Kontogiorgos ED. Fracture resistance of compromised endodontically treated teeth restored with bonded post and cores: An in vitro study. J Prosthet Dent. 2015 Sep;114(3):390-7.Pubmed PMID: 26047799.

[3]. Sadaf D. Survival Rates of Endodontically Treated Teeth After Placement of Definitive Coronal Restoration: 8-Year Retrospective Study. TherClin Risk Manag. 2020 Feb 21;16:125-131.Pubmed PMID: 32110030.

[4]. Heydecke G, Butz F, Hussein A, Strub JR. Fracture strength after dynamic loading of endodontically treated teeth restored with different post-andcore systems. J Prosthet Dent. 2002 Apr;87(4):438-45.Pubmed PMID: 12011861.

[5]. Khurshid Z, Zafar M, Qasim S, Shahab S, Naseem M, AbuReqaiba A. Advances in Nanotechnology for Restorative Dentistry. Materials (Basel). 2015 Feb 16;8(2):717-731. PubmedPMID: 28787967.

[6]. Alsamadani KH, Abdaziz el-SM, Gad el-S. Influence of different restorative techniques on the strength of endodontically treated weakened roots. Int J Dent. 2012;2012:343712.Pubmed PMID: 22666251.

[7]. Mangold JT, Kern M. Influence of glass-fiber posts on the fracture resistance and failure pattern of endodontically treated premolars with varying substance loss: an in vitro study. J Prosthet Dent. 2011 Jun;105(6):387-93. Pubmed PMID: 21640240.

[8]. Cheung W. A review of the management of endodontically treated teeth. Post, core and the final restoration. J Am Dent Assoc. 2005 May;136(5):6119.Pubmed PMID: 15966648.

[9]. Gu XH, Kern M. Fracture resistance of crowned incisors with different post systems and luting agents. J Oral Rehabil. 2006 Dec;33(12):918-23.Pubmed PMID: 17168934.

[10]. Stavropoulou AF, Koidis PT. A systematic review of single crowns on endodontically treated teeth. J Dent. 2007 Oct;35(10):761-7. PubmedPMID: 17822823.

[11]. Fernandes AS, Shetty S, Coutinho I. Factors determining post selection: a literature review. J Prosthet Dent. 2003 Dec;90(6):556-62.Pubmed PMID: 14668756.

[12]. Sterzenbach G, Franke A, Naumann M. Rigid versus flexible dentine-like endodontic posts--clinical testing of a biomechanical concept: seven-year results of a randomized controlled clinical pilot trial on endodontically treated abutment teeth with severe hard tissue loss. J Endod. 2012 Dec;38(12):155763.Pubmed PMID: 23146637.

[13]. Stankiewicz NR, Wilson PR. The ferrule effect: a literature review. IntEndod J. 2002 Jul;35(7):575-81.Pubmed PMID: 12190896.

[14]. Goldsmith M, Gulabivala K, Knowles JC. The effect of sodium hypochlorite irrigant concentration on tooth surface strain. J Endod. 2002 Aug;28(8):5759.Pubmed PMID: 12184417.

[15]. Alenzi A, Samran A, Samran A, Nassani MZ, Naseem M, Khurshid Z, et al. Restoration Strategies of Endodontically Treated Teeth among Dental Practitioners in Saudi Arabia. A Nationwide Pilot Survey. Dent J (Basel). 2018 Sep 3;6(3):44.Pubmed PMID: 30177593.

[16]. Akbar I. Knowledge, attitudes and practice of restoring endodontically treated teeth by dentists in north of saudiarabia. Int J Health Sci (Qassim). 2015 Jan;9(1):41-9.Pubmed PMID: 25901132.

[17]. Nawasrah A, Farooqi FA. Evaluating the basic knowledge and techniques of dentists about restoring endodontically treated teeth in Saudi Arabia. J Dent Oral Health. 2017;3(6):80.

[18]. Rabi T, Rabi TH. Attitudes of Palestinian dentists toward restoration of endodontically treated teeth. Int. J. Prosthodont. Restor. Dent. 2015;5(2):4450.

[19]. Sharma D, Agrawal S, Gangurde P, Agarwal S, Srichand R, Sharma V. Awareness, attitude, and practice of dental practitioners toward management of endodontically treated teeth and factors associated with it: A questionnaire descriptive survey. J Family Med Prim Care. 2020 Feb 28;9(2):1113-1118. Pubmed PMID: 32318477.

[20]. Naumann M, Neuhaus KW, Kölpin M, Seemann R. Why, when, and how general practitioners restore endodontically treated teeth: a representative survey in Germany. Clin Oral Investig. 2016 Mar;20(2):253-9.Pubmed PMID: 26082310.

[21]. Pruthi V, Talwar S, Nawal RR, Pruthi PJ, Choudhary S, Yadav S. Evaluation of retention and fracture resistance of different fiber reinforced posts: An in vitro study. J Conserv Dent. 2018 Mar-Apr;21(2):157-161.Pubmed PMID: 29674817. 